\title{
Desenvolvimento local: o Programa Um Milhão de Cisternas (P1MC) em Tupanatinga, PE
}

\author{
Local development: the Program One Million Tanks (P1MC) in Tupanatinga, PE \\ Developpement local: le Programme «Un Million de Citernes» (P1MC) à \\ Tupanatinga, PE
}

Desarrollo local: el Programa de Un Millón de Cisternas (P1MC) en Tupanatinga, PE

\author{
Dinando Antonio Soares Junior* \\ Maria do Rosário de Fátima Andrade Leitão*
}

Recebido em 24/05/2016; revisado e aprovado em 11/12/2016; aceito em 11/12/2016

DOI: http:/ /dx.doi.org/10.20435/1984-042X-2017-v.18-n.1(06)

\begin{abstract}
Resumo: O objetivo deste artigo é identificar ações relacionadas ao Desenvolvimento Local na implantação do P1MC, na região do Semiárido de Pernambuco. Assim foram mapeadas as instituições, atores sociais e as atividades do P1MC em Tupanatinga, Pernambuco, a partir especialmente, dos critérios estabelecidos no aporte teórico sobre Desenvolvimento Local. Nos resultados encontrados, percebe-se que o P1MC fomentou por meio da participação, a alguns atores sociais, a ampliação do saber fazer, em que pese ao fato de que uma parte dos beneficiários considerem de cunho político e assistencialista, as ações do Programa.
\end{abstract}

Palavras-chave: desenvolvimento local; P1MC; cisternas.

Abstract: The objective of this article is to identify actions related to local development in the implementation of the P1MC, in the semi-arid region of Pernambuco. Thus the institutions were mapped, social actors and activities in the P1MC in Tupanatinga, Pernambuco, from especially the criteria established in the theoretical framework on Local Development. The results found, realizes sure that the P1MC fomented through participation, some social actors, broaden knowing how to do, weigh the fact of the beneficiaries consider the political nature and assistencialista, the actions of the program.

Key words: local development; P1MC; tanks.

Résumé: Le but de cet article est d'identifier les actions liées au développement local à propos de la mise en œuvre du P1MC dans la région semi-aride de l'état du Pernambuco. Ainsi, les institutions, les acteurs sociaux et les activités du P1MC à Tupanatinga, Pernambuco, ont été cartographiés à partir notamment des critères établis dans le cadre théorique du développement local. Selon les résultats, il est clair que le P1MC a favorisé, par la participation de certains acteurs sociaux, le développement du savoir-faire, en dépit du fait que certains des bénéficiaires considèrent les actions du programme dotées d'une nature politique et d'assistanat.

Mots-clés: développement local ; P1MC ; citernes.

Resumen: El objetivo de este artículo es identificar las acciones relacionadas con el desarrollo local en la implementación del P1MC, en la región semiárida de Pernambuco. Así se mapearon las instituciones, actores sociales y actividades de P1MC en Tupanatinga, Pernambuco, especialmente a partir de los criterios establecidos en el marco teórico sobre el Desarrollo Local. Los resultados encontrados, dár-se cuenta de que el P1MC fomenta a través de la participación a que algunos actores sociales, amplien el saber hacer, pese a que algunos de los beneficiarios consideraren de naturaleza política y asistencialista, las acciones de dicho programa.

Palabras clave: desarrollo local; P1MC; cisternas.

\section{INTRODUÇÃO}

O artigo se propõe a identificar ações relacionadas ao Desenvolvimento Local na implantação do Programa Um Milhão de
Cisternas (P1MC), em Tupanatinga, localizado no semiárido de Pernambuco, uma região que apresenta longas estiagens, motivo pelo qual o município foi contemplado na implantação do Programa.

* Universidade Federal Rural de Pernambuco, Recife, Pernambuco, Brasil. 
O município está localizado a $308^{1}$ $\mathrm{km}$ de Recife, capital do estado de Pernambuco, constitui-se um dos territórios produtivos que faz parte da bacia leiteira que abastece as indústrias do estado.

O Programa Um Milhão de Cisternas iniciou suas atividades em 2003, a partir da Articulação do Semiárido Brasileiro $(\mathrm{ASA})^{2}$, que vem se propondo a fomentar ações de articulação e de convivência sustentável com o ecossistema do semiárido, através do fortalecimento da sociedade civil, da mobilização, envolvimento e capacitação das famílias, a partir de uma proposta de educação processual, que se operacionaliza em participação, mobilizações, reuniões, capacitações, engajamento, formação de agentes multiplicadores, das ações e habilidades propostas.

O P1MC é uma política pública que caminha na direção de solucionar questões cruciais do Semiárido nordestino, a carência de água, as consequências das secas e do coronelismo ${ }^{3}$ nesse contexto socioeconômico e ambiental, por isso, a

\footnotetext{
${ }^{1}$ Distância aferida pelo sistema de informações do Google maps, partindo do marco Zero de Recife, PE, via BR 232, ao Centro de Tupanatinga, PE. Disponível em: <http:/ / www.google.com.br/ maps/>. Acesso em: 10 set. 2014.

${ }^{2}$ No site a ASA se define em uma rede que defende, propaga e põe em prática o projeto político da convivência com o Semiárido. Formada por mais de três mil organizações da sociedade civil de distintas naturezas - sindicatos rurais, associações de agricultores e agricultoras, cooperativas, ONG's, Oscip, etc. Conecta pessoas organizadas em entidades que atuam em todo o Semiárido defendendo os direitos dos povos e comunidades da região. As entidades que integram a ASA estão organizadas em fóruns e redes, nos estados que compõem o semiárido brasileiro. Disponível em: <http://www.asabrasil.org.br/>. Acesso em: 15 jan. 2015.

${ }^{3}$ Para aprofundar o tema ver Carone (1971). A denominação de coronel incluiu os chefes políticos especialmente no sertão do Nordeste brasileiro, Carone explica o domínio de homens que centralizavam o poder de tal forma que assumiam para si o controle do município, da lei, da justiça, da igreja etc.
}

mobilização das instituições e dos atores sociais na operacionalização do Programa, são dados valorizados na pesquisa.

O Desenvolvimento Local consiste em um conceito fundamental nesta pesquisa porque inclui valores e ações presentes nestas que dialogam com o P1MC, por exemplo: mobilização social, valorização dos saberes populares, o caráter endógeno, a exploração das potencialidades locais e valorização da participação social. Na contramão desses valores, está o coronelismo, uma prática sociopolítica exercida no Nordeste brasileiro, a qual Carone (1971, p. 85-92) define em um domínio de homens que centralizavam o poder de tal forma que assumem para si o controle do município, da lei, da justiça, da igreja etc. Uma herança dessa centralização de poder consiste na dependência e submissão da sociedade o que redunda em fraca mobilização e participação social.

A partir destas reflexões, indagamos: será que o Programa Um Milhão de Cisternas, na região do Semiárido, está sendo implantado a partir dos pressupostos do Desenvolvimento Local? Outras indagações complementaram a questão norteadora: Quais as ações desenvolvidas? Quais os atores sociais que realizaram e participaram das ações? O que foi realizado nas ações? Onde foram realizadas as ações?

No processo de definição do tema, foi realizada uma pesquisa no banco de teses da CAPES, cujos resultados demonstraram a relevância do tema. Nesse acervo, foram identificadas 3.210 dissertações e teses sobre Desenvolvimento Local; mapeadas sete dissertações sobre o Programa um Milhão de Cisternas, sendo apenas um do P1MC realizada no estado de Pernambuco. Com esses dados, constata-se a carência de pesquisas sobre a implantação das Cisternas e o Desenvolvimento Local relacionado à Política Pública de Recursos Hídricos ${ }^{4}$

4 A Lei 9.433, de 08 de Janeiro de 1997, art. $1^{\circ}$, 
direcionada às necessidades da população que vive no semiárido.

Os dados da pesquisa qualitativa e exploratória foram coletados em documentos e observações participantes em visitas ao município de Tupanatinga, nas quais foram observadas algumas reuniões e capacitações do Programa. Sobre pesquisa qualitativa, Oliveira (2002, p. 117) afirma que se pode descrever a complexidade de um problema, analisar a interação de certas variáveis, compreender e classificar processos dinâmicos experimentados por grupos sociais e interpretar as particularidades dos comportamentos ou atitudes dos indivíduos. Quanto às pesquisas exploratórias, Gil (2009, p. 27) destaca que são desenvolvidas com o objetivo de proporcionar uma visão geral sobre determinado fato. $\mathrm{O}$ autor justifica a escolha por esse tipo de pesquisa quando o tema escolhido é pouco explorado, o que difículta a formulação de hipóteses precisas e operacionalizáveis.

A realização da pesquisa incluiu três etapas. A primeira etapa foi dividida em dois momentos, $\mathrm{A}$ e $\mathrm{B}$, descritos como:

A) Pesquisa documental nos arquivos do município de Tupanatinga, acervo em que foram identificados ofícios, atas de reuniões, a relação dos beneficiários das cisternas.

B) Visita ao município de Tupanatinga, realizadas durante o andamento da pesquisa, totalizando 18 visitas para coletar informações a respeito do Programa.

Na segunda Etapa da pesquisa, fez-se a sistematização dos dados a partir da elaboração de tabela e quadros.

A terceira e última Etapa, consistiu na análise dos dados a partir do conceito

parágrafo III, define que em situação de escassez, o uso prioritário dos recursos hídricos é o consumo humano e a dessedentação de animais. No mesmo artigo, agora no parágrafo VI, essa Lei ratifica, ainda, como fundamento, que a gestão dos recursos hídricos deve ser descentralizada e contar com a participação do Poder Público, dos usuários e das comunidades (BRASIL, 1997). de Desenvolvimento Local, fundamentada nos seguintes autores: Buarque (1999) e Tenório (2007).

A pesquisa buscou responder aos questionamentos acima citados, para isso foram identificadas as instituições públicas e privadas que realizaram e participaram das formações e capacitações do Programa e a relação das associações ativas e pertencentes ao município. Foi aprofundado o conhecimento do cenário do P1MC no semiárido de Pernambuco e do município de Tupanatinga. Acompanhou-se a implantação das Cisternas pela Companhia de Desenvolvimento dos Vales do São Francisco e do Parnaíba (CODEVASF), o mapeamento da implantação de Cisternas do Programa Água para todos até o final de 2014. A formação de Agentes comunitários e, por fim, a implantação de Cisternas por etapa e gênero no município de Tupanatinga.

De acordo com a FEBRABAN (2003) o Semiárido brasileiro é um dos maiores, mais populosos e também mais úmidos do mundo. A região estende-se por 868 mil quilômetros quadrados, abrangendo o norte dos Estados de Minas Gerais e Espírito Santo, os sertões da Bahia, Sergipe, Alagoas, Pernambuco, Paraíba, Rio Grande do Norte, Ceará, Piauí e uma parte do sudeste do Maranhão. E vivem nessa região mais de 18 milhões de pessoas, sendo 8 milhões na área rural. A precipitação pluviométrica é de 750 milímetros anuais, em média. Em condições normais, chove mais de 1.000 milímetros. Na pior das secas, chove pelo menos 200 milímetros, o suficiente para dar água de qualidade a uma família de cinco pessoas por um ano (FEBRABAN, 2003).

\subsection{O Programa Um Milhão de Cisternas}

A ASA informa que um dos principais objetivos do P1MC consiste em garantir água e alimentação de qualidade e, consequentemente, a melhoria das 
condições de sobrevivência da população residente no semiárido. Mas, para se chegar à água e seus benefícios no P1MC, a ASA propôs os seguintes caminhos a serem percorridos: o cadastramento e a seleção de famílias, essa etapa envolve comunidades, famílias e organizações da sociedade civil em um processo de mobilização social, que orienta toda a prática pedagógica do P1MC.

A partir dos critérios pré-definidos na estrutura do programa são selecionadas as comunidades e famílias que estejam inscritas no Cadastro Único (CadÚnico ${ }^{5}$ ) para programas sociais. Entre os critérios estabelecidos estão: a mulher como chefe de família; família de baixa renda; família com crianças de 0 a 6 anos; famílias com crianças e adolescentes frequentando a escola; adultos com idade igual ou superior a 65 anos; deficientes físicos e/ ou mentais; e a família residente na zona rural sem acesso à água encanada em quantidade e qualidade suficientes para o consumo humano e para produção de alimentos e criação de animais.

Após o processo de seleção das famílias, a outra etapa consistiu em participarem do Curso de Gerenciamento de Recursos Hídricos (GRH), o qual abordou questões relacionadas ao semiárido, aos cuidados com a água e com a cisterna.

Outras capacitações realizadas no P1MC se constituíram em processos de

\footnotetext{
${ }^{5}$ O Ministério do Desenvolvimento Social e Combate à Fome (MDS) é responsável pela coordenadoria do CadÚnico. O sistema é de uso obrigatório nas seleções de beneficiários de programas sociais promovidos pelo Governo Federal, como por exemplo o Programa Cisternas. O Cadastro Único (CadÚnico) é um sistema que identifica e caracteriza as famílias de baixa renda, e obtém dados que mostram a realidade socioeconômica dessas famílias, trazendo informações de todo o núcleo familiar, das características do domicílio, das formas de acesso a serviços públicos essenciais e, também, dados de cada um dos componentes da família. Disponível em: <http:/ / www.programadogoverno.org>. Acesso em: 15 jan. 2015.
}

formação de diferentes atores que participaram do Programa, entre eles: as famílias, as comissões municipais e pedreiros e pedreiras que construíam as cisternas. A proposta de formação incluiu a escolha de metodologia participativa e reflexiva, com o objetivo de ampliar as reflexões das famílias rurais e dos grupos a respeito do direito à água e das possibilidades de convivência com o semiárido. Os discursos oficiais sobre o Programa informam que as decisões metodológicas para o processo de sensibilização e motivação nas capacitações foram definidas a partir dos conhecimentos e práticas endógenas, agregando novos conhecimentos, na perspectiva da construção coletiva.

Essas capacitações foram precedidas por um processo de mobilização de instituições públicas e privadas e da sociedade civil em geral. As mobilizações redundaram na formação das comissões municipais; essa prática, segundo o discurso oficial, objetivava o aumento de participação dos atores sociais e a interação entre as comissões comunitárias e as famílias provenientes da agricultura familiar. As capacitações também se constituíram em espaços de novas mobilizações, ao incluir outras organizações que ainda não haviam participado do processo.

Em consequência destas capacitações surgiram agentes multiplicadores e por fim, a terceira etapa de capacitações incluiu a construção das cisternas de placas de 16 mil litros. Esses momentos formativos, segundo o discurso oficial, se propuseram a difundir os conteúdos práticos sobre a construção das cisternas, também discutir os conteúdos centrais da proposta de convivência com o semiárido e da importância da implantação das cisternas como elemento mobilizador das famílias rurais. As capacitações de construção de cisternas foram destinadas aos/ às agricultores/as familiares com interesse em desenvolver uma nova atividade para complemento de renda. Após a formação construtiva das cisternas, o passo seguinte 
constituiu-se na capacitação sobre a implantação das cisternas de 16 mil litros.

A proposta construtiva dessas cisternas incluiu uma opção de baixo custo, a partir da utilização de placas de cimento pré-moldadas, construídas e implantadas ao lado das casas, trabalho realizado por pessoas da própria comunidade, capacitadas nos cursos de pedreiros/as oferecidos pelo P1MC. O processo construtivo fez parte da estratégia de mobilização das famílias, cuja mão de obra se constituiu em contrapartida, ou seja, possibilitou o engajamento e colaboração da comunidade nas ações do Programa, o que fortaleceu a organização comunitária, por meio dos mutirões. Trata-se de uma tecnologia simples, adaptada à região semiárida. As cisternas apresentam um formato cilíndrico, coberta e fica semienterrada. O seu funcionamento prevê a captação de água da chuva aproveitando o telhado da casa, que escoa a água através de calhas.

O programa P1MC foi criado e iniciado pela ASA em 2003 e finalizado em 2012 pelo Ministério do Desenvolvimento Social e combate à Fome (MDS), data na qual ele foi substituido pelo Programa Água para $\operatorname{Todos}^{6}$ do Ministério da Integração Social (MI) dando continuidade às ações do P1MC.

O P1MC, não conseguiu atender a demanda total do programa que era a implantação de 1.000 .000 de cisternas

\footnotetext{
${ }^{6}$ O Programa Água para Todos foi instituído pelo Decreto n. 7.536 de 26 de julho de 2011. É uma ação do Governo Federal coordenada pelo Ministério da Integração Nacional, por meio da Secretaria de Desenvolvimento Regional, que tem como parceiros diversas instituições federais, estaduais, municipais além de organizações da sociedade civil. Visa promover a universalização do acesso e uso da água em áreas rurais para consumo humano e para produção agrícola alimentar e nutricional da família em situação de vulnerabilidade social, promovendo a implantação de cisternas entre outros sistemas simplificados de abastecimento de água, para atender prioritariamente as populações de baixa renda em comunidades difusas do semiárido brasileiro.
}

no semiárido brasileiro, e, nesse período, foram construídas no município de Tupanatinga, no ano de 2004, 40 cisternas, atendendo cerca de 200 pessoas.

A partir de 2012, por meio do Programa Água para Todos do Ministério da Integração Social (MI), se deu continuidade as ações do P1MC com a empresa de Engenharia de Construção Civil Ltda (ENGECOL), que foi a responsável pela implantação das Cisternas de polietileno em Tupanatinga, coordenada pela CODEVASF; no período de 2012 a 2014 foram instaladas 1.413 Cisternas.

As Cisternas de Polietileno, diferentemente das de placas, são industrializadas. Apresentam o formato cilíndrico e estão prontas para a instalação no local. Possui a capacidade de armazenar até 16 mil litros de água, e sua instalação segue a mesma estrutura, são semienterradas, com instalação de tubulações que direcionam a água que cai das calhas dos telhados das casas para a Cisterna ${ }^{7}$.

\section{ALGUMAS REFLEXÕES TEÓRICAS}

O Programa Um Milhão de Cisternas se constitui pela organização de seis componentes: o Controle Social, a Capacitação, o Fortalecimento Institucional, a Comunicação, a Construção de Cisternas e a Mobilização, este último permeia todos os demais.

Segundo os documentos oficiais, a mobilização social e os processos educacionais proporcionados pelo P1MC vão além do aspecto quantitativo que pode ser traduzido no número de cisternas construídas. Eles envolvem reflexões sobre a vida comunitária, novas formas de participação e organização popular, o estímulo à criatividade no acesso a políticas públicas.

Para Buarque (1999, p. 29), os debates e as reflexões que dominam o cenário científico internacional sobre modelos e

\footnotetext{
${ }^{7}$ As cisternas de Polietileno apresentam uma durabilidade de 10 anos, já as de placas podem durar de 20 anos a mais.
} 
alternativas de desenvolvimento enfrentam desafios e problemas econômicos, sociais e ambientais contemporâneos. E o autor complementa que esses debates estão levando à formação de uma nova concepção de desenvolvimento, conhecida como Desenvolvimento sustentável (BUARQUE, 1999, p. 29). A definição de desenvolvimento sustentável proposta pela World Commission on Evironment and Development (WCED, 1987, p. 2-5) é aquela que satisfaz as necessidades do presente, sem comprometer a capacidade de as gerações futuras satisfazerem as suas próprias necessidades.

Esta é uma resposta aos problemas de desigualdades sociais, das necessidades de melhor qualidade de vida de uma parcela significativa da população mundial, podendo ser na área ambiental e/ou socioeconômica, gerada pelo estilo de crescimento local, que tende a limitar as oportunidades de as gerações futuras permanecerem em sua região.

Neste estudo, consideramos a implantação do Programa Um Milhão de Cisternas na perspectiva do Desenvolvimento Local na região do Semiárido de Pernambuco.

Segundo De Jesus (2003, p. 72) o Desenvolvimento Local:

Trata-se de um esforço localizado e concertado, isto é, são lideranças, instituições, empresas e habitantes de um determinado lugar que se articulam com vistas a encontrar atividades que favoreçam mudanças nas condições de produção e comercialização de bens e serviços, de forma a proporcionar melhores condições de vida aos cidadãos e cidadãs, partindo da valorização e ativação das potencialidades e efetivos recursos locais.

A participação consiste em uma das potencialidades dos processos de Desenvolvimento Local para comunidades, bairros, cidades etc. Segundo Tenório (2007, p. 101) o Desenvolvimento Local:
[...] deve se dar por dentro de processos participativos nos quais a cidadania, de forma individual ou por meio de seus diferentes agentes na sociedade civil, em diálogo com o poder público e o mercado, propõe soluções planejadas em prol do local/regional. A preocupação, portanto, deve ser mais com o processo decisório do que na solução dos problemas locais, do "como" e não do "através", da participação [...].

Buarque (1999, p. 09) diz que o Desenvolvimento Local "é um processo endógeno registrado em pequenas unidades territoriais e agrupamentos humanos capaz de promover o dinamismo econômico e a melhoria da qualidade de vida da população". Para o autor, representa uma singular transformação nas bases econômicas e na organização social em nível local, resultante da mobilização das energias da sociedade, explorando as suas capacidades e potencialidades específicas. E reforça que o Desenvolvimento Local é consistente e sustentável, deve elevar as oportunidades sociais e a viabilidade e competitividade da economia local, aumentando a renda e as formas de riqueza, ao mesmo tempo em que assegura a conservação dos recursos naturais.

E para Buarque (1999, p. 9), mesmo com as imprecisões que ainda cercam o conceito, todos os esforços recentes de Desenvolvimento Local e municipal têm incorporado, de alguma forma, os postulados de sustentabilidade, procurando assegurar a permanência e a continuidade, no médio e longo prazo, dos avanços e melhorias na qualidade de vida, na organização econômica e na conservação do meio ambiente.

\section{O P1MC EM TUPANATINGA}

Nos arquivos do município, foram identificados os seguintes documentos referentes ao Programa Água para todos: Ofício n. 08/2014; Ofício n. 045/2014; Lista 
de Presença de Comissões Comunitárias, Ata de Reunião para apresentação do Programa; Ata de Capacitação; Ata de Reunião com os Agentes de Saúde; Ata de Reunião com a Equipe Técnica das Cisternas; Ata de Reunião com a Equipe Técnica da CODEVASF; Ata de Reunião com o comite Gestor para Elaboração do Cronograma de distribuição das Cisternas; Ata de Reunião com o comitê Gestor do Programa, Agentes de Saúde e membros da comunidade para apresentação do SSAA (Sistema Simplificado de Abestecimento de Água) e, por fim, a Relação de Beneficiários para Cisternas Familiares. Assim, os documentos tinham informações das instituições que participaram do processo de implantação do Programa no município, da empresa que implantou as Cisternas, em quantas etapas foram realizadas e o número de munícipes atendidos pelo Programa.
Para o andamento da pesquisa, foram realizadas doze visitas ${ }^{8}$ no período de janeiro a junho de 2014, e seis visitas, no período de fevereiro a abril de 2015, ao município de Tupanatinga do estado de Pernambuco, para se levantar informações a respeito do Programa.

Os dados expostos no quadro 1 mostram a participação de Instituições Públicas e Privadas e Organizações da Sociedade Civil no processo de implantação do P1MC no município de Tupanatinga. Constata-se a participação de 12 Instituições e Organizações da Sociedade Civil, com um total de 27 participantes que se reuniram para realizar as seguintes atividades: Apresentar o programa aos participantes, capacitar os agentes das ações e formar multiplicadores das informações do programa no município de Tupanatinga, com a intenção de mobilizar as instituições e sociedade civil do município.

\begin{tabular}{|c|l|c|c|c|}
\hline $\mathbf{N}^{\mathbf{0}}$ & Instituições & $\begin{array}{c}\text { Atividade(s) } \\
\text { Realizada(s) }\end{array}$ & $\begin{array}{c}\text { Quant. de } \\
\text { reuniões }\end{array}$ & $\begin{array}{c}\text { Quant. de } \\
\text { Participantes }\end{array}$ \\
\hline 1 & CODEVASF & $1^{1}, 2^{2} 3^{3}, 4^{4}, 5^{5}$ & 10 & 02 \\
\hline 2 & Secretaria de Agricultura de Tupanatinga & $6^{6}$ & 10 & 02 \\
\hline 3 & Secretaria de Educação de Tupanatinga & 6 & 10 & 01 \\
\hline 4 & Secretaria de Ação Social de Tupanatinga & 6 & 10 & 02 \\
\hline 5 & Secretaria de Saúde de Tupanatinga & 6 & 10 & 02 \\
\hline 6 & Secretaria de Infraestrutura de Tupanatinga & 6 & 10 & 02 \\
\hline 7 & $\begin{array}{l}\text { Secretaria de Desenvolvimento Econômico } \\
\text { de Tupanatinga }\end{array}$ & 6 & 10 & 02 \\
\hline 8 & $\begin{array}{l}\text { Conselho Municipal de Desenvolvimento } \\
\text { Rural Sustentável - CMDRS }\end{array}$ & 6,3 & 10 & 01 \\
\hline 9 & ENGECOL & $6,3,7^{7}$ & 01 & 01 \\
\hline 10 & Associações do Município & 8 & 01 & 09 \\
\hline 11 & Igreja Católica & 8 & 10 & 01 \\
\hline 12 & Igreja Evangélica & - & 10 & 02 \\
\hline Total & & 8 & 27 \\
\hline
\end{tabular}

Quadro 1 - Atividades para Implantação do P1MC no município de Tupanatinga, PE Legenda: ${ }^{1}$ Apresentar o programa P1MC e Água para Todos; ${ }^{2}$ Realizar reuniões e a formação de Agentes comunitários; ${ }^{3}$ Identificar os locais para implantação do P1MC; ${ }^{4}$ Capacitar Agentes locais; ${ }^{5}$ Acompanhar a implantação do programa; ${ }^{6}$ Realizar reuniões e a formação de Agentes comunitários; ${ }^{7}$ Implantar as cisternas; ${ }^{8}$ Participar e Realizar reunião para multiplicar as informações do P1MC e água para todos nas comunidades.

Fonte: Elaborado pelos autores com base em documentos do CMDRS de Tupanatinga, PE.

\footnotetext{
${ }^{8}$ Dentre as reuniões realizadas para o processo de implantação do programa estão as seguintes datas: 19 e $29 / 03,11 / 04,11 / 05,10 / 07,16 / 07,10 / 09$ de 2012, 07/05 de 2013, 19/03, 03/09 de 2014.
} 
O quadro 2 explicita as atividades desenvolvidas por cada instituição no processo de execução e implantação do P1MC no município de Tupanatinga. A escolha do público alvo a ser beneficiado foi fundamentada nos seguintes critérios: Famílias cadastradas no CadÚnico; Mulheres chefes de Famílias; Renda mensal de até três salá- rios mínimos; Famílias com crianças de 0 a 6 anos; Crianças e adolescentes frequentando a escola; Adultos com idade igual ou superior a 65 anos e as Famílias com pessoa(as) que apresentarem deficiência(s) física(s) e/ou mental(ais). Nas famílias contempladas se identificam o preenchimento da maioria dos critérios citados.

\begin{tabular}{|c|c|c|}
\hline Instituiçõos & Objetivos & $\begin{array}{l}\text { Seleção das famílias a serem } \\
\text { contempladas pelo P1MC }\end{array}$ \\
\hline ASA & $\begin{array}{l}\text { - Descentralizar e Democratizar a água. } \\
\text { - Possibilitar a diminuição da incidência de doenças em virtude do } \\
\text { consumo de água contaminada e a diminuição da sobrecarga de } \\
\text { trabalho das mulheres nas atividades domésticas. } \\
\text { - Possibilitar avanços não só para as famílias, mas para as comuni- } \\
\text { dades rurais como um todo, como o aumento da frequência escolar. } \\
\text { - Estimular à organização comunitária. } \\
\text { - Capacitar os diversos atores que participam do Programa: famí- } \\
\text { lias, comissões municipais e pedreiros e pedreiras. } \\
\text { - Ampliar as reflexões das famílias rurais e dos grupos a respeito } \\
\text { do direito à água e das possibilidades de convivência com o Semi- } \\
\text { árido. } \\
\text { - Reconhecer sua capacidade de luta e defesa de seus direitos, se- } \\
\text { jam eles o acesso à água, a uma educação contextualizada e de qua- } \\
\text { lidade, ao crédito, à preservação das sementes crioulas, ao direito } \\
\text { de se comunicar, entre tantos outros. } \\
\text { - Melhorar a vida das famílias que vivem na Região Semiárida do } \\
\text { Brasil, garantindo o acesso à água de qualidade é o principal obje- } \\
\text { tivo do Programa. }\end{array}$ & $\begin{array}{l}\text { - Etapa que envolve comunida- } \\
\text { des, famílias e organizações da } \\
\text { sociedade civil em um proces- } \\
\text { so de mobilização social, que } \\
\text { orienta toda a prática pedagó- } \\
\text { gica do P1MC. } \\
\text { - As comunidades e famílias } \\
\text { são selecionadas a partir dos } \\
\text { critérios pré-definidos na es- } \\
\text { trutura do programa e que } \\
\text { estejam inscritas no Cadastro } \\
\text { Único para Programas Sociais } \\
\text { (CadÚnico). } \\
\text { - Depois de selecionadas as fa- } \\
\text { mílias participam do Curso de } \\
\text { Gerenciamento de Recursos } \\
\text { Hídricos (GRH) que aborda } \\
\text { questões como relacionadas ao } \\
\text { Semiárido e ao cuidado com a } \\
\text { cisterna e a água. }\end{array}$ \\
\hline CODEVASF & $\begin{array}{l}\text { - Mobilizar as políticas públicas locais para a implantação do } \\
\text { P1MC. } \\
\text { - Formar grupos gestores locais. } \\
\text { - Capacitar os agentes Locais. } \\
\text { - Acompanhar a implantação do P1MC no município de Tupanatinga. }\end{array}$ & $\begin{array}{l}\text { - Orientar os gestores e agentes } \\
\text { comunitários quanto a implan- } \\
\text { tação do P1MC }\end{array}$ \\
\hline CMDRS & $\begin{array}{l}\text { - Promover reuniões com as políticas públicas locais para a aquisi- } \\
\text { ção e implantação do P1MC em Tupanatinga. } \\
\text { - Mobilizar a sociedade civil para as reuniões e capacitações do } \\
\text { P1MC no município de Tupanatinga. } \\
\text { - Organizar e registrar em documentos os eventos realizados pelo } \\
\text { P1MC no município de Tupanatinga. } \\
\text { - Acompanhar a implantação das cisternas no município de Tupa- } \\
\text { natinga. }\end{array}$ & $\begin{array}{l}\text { - Identificar as famílias que po- } \\
\text { dem ser atendidas pelo P1MC. } \\
\text { - Acompanhar a implantação } \\
\text { das cisternas }\end{array}$ \\
\hline CGM & $\begin{array}{l}\text { - Apresentar à coordenação do programa as famílias que realmente } \\
\text { necessitam da Cisterna e acompanhar o processo de instalação } \\
\text { - Promover reuniões com as políticas públicas locais para implan- } \\
\text { tação do programa em Tupanatinga. } \\
\text { - Mobilizar a sociedade civil para as reuniões e capacitações do } \\
\text { programa no município. } \\
\text { - Organizar e registrar em documentos os eventos realizados pelo } \\
\text { programa no município de Tupanatinga. }\end{array}$ & $\begin{array}{l}\text { - Identificar as famílias que po- } \\
\text { dem ser atendidas pelo P1MC. } \\
\text { - Acompanhar a implantação } \\
\text { das cisternas }\end{array}$ \\
\hline ENGECOL & $\begin{array}{l}\text { - Acompanhar e Implantar o P1MC no município de Tupanatinga. } \\
\text { - Identificar os locais da implantação das Cisternas em Tupanatinga. }\end{array}$ & $\begin{array}{l}\text { - Acompanhar a implantação } \\
\text { das cisternas. }\end{array}$ \\
\hline
\end{tabular}

Quadro 2 - Ações desenvolvidas pelas intituições envolvidas com a implantação do P1MC

Fonte: Elaborado pelos autores com base nos Arquivos do município de Tupanatinga. 
Ainda com base em documentos dos arquivos do município, o quadro 3 identifica as Associações e Organização da Sociedade Civil que se envolveram no processo de implantação do P1MC no município.

\begin{tabular}{|c|l|c|c|c|}
\hline \multirow{2}{*}{$\mathbf{N}^{\mathbf{0}}$} & \multirow{2}{*}{$\begin{array}{l}\text { Nome da Comunidade/ } \\
\text { Instituição(ões) }\end{array}$} & $\begin{array}{c}\text { Quantidade } \\
\text { de Represen- } \\
\text { tantes }\end{array}$ & \multicolumn{2}{|c|}{ Percentual } \\
\cline { 3 - 5 } & Associação & Município \\
\hline 1 & Associação Sítio Laranjo & 1 & $2,5 \%$ & $6,4 \%$ \\
\hline 2 & Associação Sítio Serra dos Dé & 1 & $5 \%$ & $3,2 \%$ \\
\hline 3 & Associação Sítio Uburana & 1 & $3,3 \%$ & $4,8 \%$ \\
\hline 4 & Associação Sítio Lopes & 1 & $3,3 \%$ & $4,8 \%$ \\
\hline 5 & Associação Sítio Canela & 3 & $12 \%$ & $4 \%$ \\
\hline 6 & Assentamento Cachoeira Grande & 3 & $12 \%$ & $4 \%$ \\
\hline 7 & Associação Sítio Sapato & 1 & $2 \%$ & $8 \%$ \\
\hline 8 & Associação dos Pequenos Produtores Rurais Sítio Gritos & 2 & $6,6 \%$ & $4,8 \%$ \\
\hline 9 & Associação Sítio Gritos & 1 & $3,3 \%$ & $4,8 \%$ \\
\hline \multicolumn{2}{|c|}{ Total } & 14 & $50 \%$ & $44,8 \%$ \\
\hline
\end{tabular}

Quadro 3 - Instituições participantes da formação e capacitação da Comissão Comunitária do Programa em Tupanatinga, datada em 03/09/2014

Fonte: Elaborado pelos Autores com base nos documentos do CMDRS de Tupanatinga.

A proposta de participação de representantes das Associações e Assentamento passam a dispor de informações como orientar os associados a realizarem seus cadastros no CadÚnico, ou seja, transformam-se em agentes multiplicadores das informações. Preenchimento do cadastro se constituiu no primeiro passo para estarem aptos a serem comtemplados pelo P1MC, a partir das informações cadastradas se avaliavam as solicitações a partir dos critérios de acessibilidade ao Programa. Dessa forma, as Associações e Assentamento se integraram no processo de mobilização e organização da Sociedade Civil.

Vale ressaltar que, no que se refere ao percentual de participação das associações e assentamento, ela não foi homogênea, conforme pode ser constatada nos seguintes dados: a Associação Sítio Laranjo com um representante, correspondendo a 2,5\% da associação e 6,4\% do total de associações ativas no município; a Associação Sítio Serra dos Dé com um representante, correspondendo a $5 \%$ da associação e 3,2\% do total de associações ativas no município; a Associação Sítio Uburana com um representante, correspondendo a 3,3\% da associação e $4,8 \%$ do total de associações ativas no município; a Associação Sítio Lopes com um representante, correspondendo a 3,3\% da associação e $4,8 \%$ do total de associações ativas no município; a Associação Sítio Canela com três representantes, correspondendo a $12 \%$ da associação e $4 \%$ do total de associações ativas no município; o Assentamento Cachoeira Grande com três representantes, correspondendo a $12 \%$ do assentamento e $4 \%$ do total de associações ativas no município; a Associação Sítio Sapato com um representante, correspondendo a $2 \%$ da associação e $8 \%$ do total de associações ativas no município; a Associação dos Pequenos produtores Rurais sítio gritos com dois representantes, correspondendo a $6,6 \%$ da associação e $4,8 \%$ do total de associações ativas no município; e, por fim, a Associação Sítio gritos com um representante, correspondendo a 3,3\% da associação e 4,8\% do total de associações ativas no município.

Com base em dados dos documentos do município, listamos as associações que participaram da formação de membros comunitários para a instalação das Cisternas, dentre as associações, os 
quantitativos de famílias contempladas: a Associação Sítio Laranjo com 28 famílias contempladas; a Associação Sítio Serra dos Dé com 14 famílias contempladas; a Associação Sítio Uburanas com oito famílias contempladas; a Associação Sítio Lopes com seis famílias contempladas; a Associação Sítio Canela com 35 famílias contempladas; a Assentamento Cachoeira Grande com 12 famílias contempladas; a Associação Sítio Sapato com 18 famílias contempladas; e a Associação Sítio Gritos com três famílias contempladas.

A tabela 1 sintetiza informações sobre o processo de capacitação no qual participaram onze representantes de nove instituições, com quarenta e um multiplicadores do P1MC. No total foram 1.413 famílias beneficiadas, os dados indicam que a maioria são mulheres por se constituir em um dos critérios estabelecidos pelo Programa.

Tabela 1 - Instalação de Cisternas e Formação de Agentes comunitários

\begin{tabular}{|c|c|c|c|c|c|}
\hline \multirow{2}{*}{$\begin{array}{l}\text { Instituições / } \\
\text { Empresas }\end{array}$} & \multirow{2}{*}{$\begin{array}{c}\text { Formação de } \\
\text { Membros } \\
\text { Comunitários }\end{array}$} & \multirow{2}{*}{$\begin{array}{l}\text { Etapas } \\
\text { realizadas }\end{array}$} & \multirow{2}{*}{$\begin{array}{l}N^{0} \text { de Cisternas Instala- } \\
\text { das em Tupanatinga, PE }\end{array}$} & \multicolumn{2}{|c|}{$\begin{array}{c}\text { Quantidade e Percentual } \\
\text { de Beneficiários/as }\end{array}$} \\
\hline & & & & Homens & Mulheres \\
\hline \multirow{3}{*}{$\begin{array}{l}\text { ENGECOL / } \\
\text { CODEVASF }\end{array}$} & \multirow{3}{*}{$\begin{array}{c}09 \\
\text { Associações }\end{array}$} & $1^{\mathrm{a}}$ & 935 & \multirow{3}{*}{253} & \multirow{3}{*}{1.160} \\
\hline & & $2^{a}$ & 65 & & \\
\hline & & $3^{a}$ & 413 & & \\
\hline Total & & & 1.413 & $17.90 \%$ & $82.10 \%$ \\
\hline
\end{tabular}

Fonte: Elaborado pelos autores com base nos Arquivos do CMDRS.

Assim, os dados dos quadros 1, 2 e 3 , e da tabela 1, embasados em documen$\operatorname{tos}^{9}$ do lócus da pesquisa e de instituições públicas e/ou privadas consistiram na sistematização de dados quantitativos para subsidiar a análise qualitativa.

As reuniões e as capacitações do P1MC no município de Tupanatinga eram organizadas por instituições públicas e privadas. Essas instituições conduziram as reuniões e seus agendamentos num processo de mobilização, capacitação, formação de agentes sociais e da participação da sociedade civil. Essas reuniões aconteciam em prédios Públicos pertencentes ao município.

As formações e as capacitações do CGM, Agentes de Sáude e Equipes Técnicas ocorriam no centro do município, já as capacitações das Famílias Agricultoras aconteciam nas associações próximas às residências das famílias beneficiadas com as Cisternas do Programa.

\footnotetext{
${ }^{9}$ As cópias dos documentos pertencentes aos arquivos do município de Tupanatinga estão anexadas ao dossiê que originou este texto.
}

Algumas características do P1MC que dialogam com o Desenvolvimento Local se constituem:

- No baixo investimento por posto de trabalho que se caracterizou pela centralização das reuniões em alguns prédios públicos e privados, para a capacitação do profissional em técnicas de construção, e na realização de mutirões durante a construção e implantação das Cisternas. O baixo capital investido por unidade produzida foi possibilitado também pelo aproveitamento da areia do próprio local, água de pequenos açudes e/ou barreiros e na aquisição de cimento, tela e ferro no comércio local.

- No potencial de geração de empregos que foi constado na contratação, quando necessária, de pedreiros e pedreiras capacitados pelo Programa.

- Na pequena escala de produção, por se tratar de produção e consumo dentro do município, com o total de 40 Cisternas de Placas, o mesmo não se pode afirmar das 1413 Cisternas de Polietileno.

- No alto grau de adaptabilidade ao ambiente sociocultural se deu pela 
necessidade das famílias agricultoras terem acesso a água, pelo envolvimento nas experiências do Programa a partir da cooperação e mobilização dos diferentes agentes sociais.

- Na economia no uso de recursos naturais faz parte de toda concepção do Programa, por utilizar as águas pluviais, de pequenos açudes e barreiros, garantindo o armazenamento e o uso de recursos renováveis.

Uma das premissas do Desenvolvimento Local é que seja endógeno o que significa atender às necessidades e demandas da população local através da participação ativa da comunidade envolvida. O Programa atende a essa característica endógena ao ser criado pela ASA, que propôs o fomento de ações de articulação e de convivência sustentável com o ecossistema do Semiárido. A organização não governamental (ASA) que conecta as instituições e organizações que atuam em todo o Semiárido brasileiro defendendo os direitos dos povos e comunidades da região no que se refere ao acesso à água e alimentação de qualidade e, consequentemente, à melhoria das condições de sobrevivência da população residente no Semiárido. A ASA em diálogo com MDS põe em prática a proposta do P1MC.

As características do Programa são endógenas, mas, no seu processo de operacionalização, o P1MC chega pronto ao município, sendo moldado à realidade local pela atuação dos diferentes atores sociais. Houve a necessidade da criação de um entorno institucional em Tupanatinga ao redor do P1MC, o que proporcionou aproveitamento dos recursos e dos serviços locais, bem como da cooperação entre os atores sociais. O fortalecimento da rede criada pelas diversas instituições que participaram do P1MC em Tupanatinga é fruto de um território ativo, de um movimento encabeçado pela ASA para criação de um novo paradigma de convivência com o Semiárido.
Pode-se afirmar que o P1MC, ao mobilizar e provocar a participação ativa de diversos segmentos sociais, provocou uma quebra de paradigma ${ }^{10}$, no qual há atuação do Estado na construção de políticas participativas. No levantamento dos dados catalogados em Tupanatinga, concordamos quando Oliveira (2007, p. 86) afirma que:

A construção participativa busca construir modelos nos quais a comunidade local possa se envolver direta e coletivamente na solução do problema, embora com alguma forma de centralização que coordena esforços locais. A idéia é que autorizando os cidadãos, em condições mais iguais, é um bem intrínseco, e um meio de assegurar uma distribuição mais justa das decisões, sendo também uma estratégia importante para alcançar soluções mais efetivas a problemas coletivos. Assim, nutrindo uma maior igualdade de poder, se está construindo uma sociedade mais democrática, e uma democracia mais deliberativa.

\section{CONSIDERAÇÕES FINAIS}

Ao longo do texto aqui desenvolvido, procurou-se identificar ações e valores do Desenvolvimento Local no processo de implantação do P1MC em Tupanatinga. O P1MC em seu processo de implantação, em conjunto com o Programa Água para Todos, articulou 12 instituições públicas e privadas, 27 representantes da Sociedade Civil. Predominou a utilização de metodologias participativas na formação de agentes multiplicadores selecionados entre as diversas representações de diferentes segmentos sociais locais.

\footnotetext{
${ }^{10}$ A quebra de paradigma refere-se ao rompimento com o modelo tradicional de se fazer política pública, no qual os administradores públicos não construíam os projetos de atuação conjuntamente, ou, simplesmente, nem consultavam o público interessado (OLIVEIRA, 2007, p. 24).
} 
Outras atividades operacionais do P1MC consistiram em reuniões de capacitações e formação dos atores sociais, nas 10 reuniões realizadas, congregou-se um total de 190 participantes, o que resultou em articulação das instituições públicas e privadas com as famílias agricultoras. As reuniões, as explicitações dos critérios possibilitaram algum grau de mobilização e controle social, inerentes aos princípios de participação e de certa autonomia social presentes nas concepções de Desenvolvimento Local.

As Cisternas resultam em produto final do P1MC, mas também em uma ferramenta de articulação de convivência com o Semiárido. Dialoga com os princípios do Desenvolvimento Local ao se tratar de uma produção em pequena escala, com a mobilização das instituições do município, com as capacitações das Famílias Agricultoras e das Equipes Técnicas e com a formação de agentes sociais.

\section{REFERÊNCIAS}

ARTICULAÇÃO SEMIÁRIDO BRASILEIRO. Programa Um Milhão de Cisternas. Disponível em: <http://www.asabrasil.org.br/>. Acesso em: 15 jan. 2015.

BRASIL. Lei n. 9.433 de 8 de janeiro de 1997. Brasília, DF, 1997. Disponível em: <http:// www.planalto.gov.br/ccivil_03/leis/L9433. htm>. Acesso em: 10 mar. 2016.

BUARQUE, Sérgio JoséCavalcanti. Metodologia de planejamento do Desenvolvimento Local e municipal sustentável. Projeto de Cooperação Técnica INCRA/IICA. PCT - INCRA/IICA. Brasília, jun. 1999. 104p.

CARONE, Edgar. Coronelismo: definição histórica bibliografia. Revista de Administração de Empresas, São Paulo, v. 11, n. 3, p. 85-92, jul./set. 1971.

COMPANHIA DE DESENVOLVIMENTO DOS VALES DO SÃO FRANCISCO E DO PARNAÍBA (CODEVASF). Ação faz parte do programa Água para Todos e integra as estratégias do governo federal de convivência com a seca.
Disponível em: <http://www.brasil.gov. br/infraestrutura/>. Acesso em: 10 jan. 2015.

CONSELHO MUNICIPAL DE DESENVOLVIMENTO RURAL SUSTENTÁVEL. Termo de Conferência de Quantitativos de Cisternas Instaladas no município de Tupanatinga, PE, 19 de março de 2014.

Oficio n. 045/2014. Tupanatinga, PE, 10 de setembro de 2014.

DE JESUS, P. Desenvolvimento Local. In: CATTANI, Antonio David (Org.). A outra economia. Porto Alegre, RS: Veraz, 2003.

FEDERAÇÃO BRASILEIRA DE BANCOS (FEBRABAN). O Semi-árido. Dados do Projeto Cisternas. 2003. Disponível em: <http:// www.febraban.org.br/arquivo/destaques/ destaque-fomezero_semiarido.asp $>$. Acesso em: 10 jan. 2014.

GIL, Antônio Carlos. Métodos e técnicas de pesquisa social. 6. ed. São Paulo: Atlas, 2009.

MINISTÉRIO DE DESENVOLVIMENTO SOCIAL E COMBATE A FOME (MDS). Cadúnico - Cadastro Único do Governo Federal. Disponínel em: <http://www. programadogoverno.org>. Acesso em: 15 jan. 2015.

OLIVEIRA, Gevaci Carlos Perroni Gama de. Desenvolvimento endógeno e local: estudo do projeto urbanizador social de Porto Alegre/ RS. 2007. 86p. Dissertação (Mestrado em Economia do Desenvolvimento) - Faculdade de Administração, Contabilidade e Economia, Pontifícia Universidade Católica do Rio Grande do Sul, Porto Alegre, RS, 2007.

OLIVEIRA, Silvio Luiz. Tratado de metodologia científica. São Paulo: Pioneira/Thomson Learning, 2002. p. 116-117.

TENÓRIO, Fernando G. Cidadania e desenvolvimento local. Rio de Janeiro: FGV; Ijuí, RS: Ed. Unijuí, 2007.

WORLD COMMISSION ON EVIRONMENT AND DEVELOPMENT (WCED). Report by the World Commission on Evironment and Development: our common future. Kenya, 1987, p. 2-5. Disponível em: <http://www. un-documents.net/wced-ocf.htm>. Acesso em: 15 abr. 2014. 


\section{Sobre os autores:}

Dinando Antonio Soares Junior: Departamento deEducação, Ciências Agrárias, Mestrado. Universidade Federal Rural de Pernambuco (UFRPE). E-mail: dinandosj@gmail.com

Maria do Rosário de Fátima Andrade Leitão: Professora Doutora Titular da Universidade Federal Rural de Pernambuco (UFRPE). E-mail: rosário@dlch.ufrpe.br 
